\title{
O NÃO-ESTADO DE DIREITO E DE “BEM-ESTAR SOCIAL” QUE REPRODUZ A EXCLUSÃO SOCIAL NA AMÉRICA DO SUL ${ }^{1}$
}

\author{
Alexandre Reis Nascimento
}

\section{Resumo}

O presente trabalho analisa O Não-Estado de Direito e de "Bem-Estar Social" que reproduz a exclusão social na América do Sul. O enfoque direciona-se para um discurso político e econômico na América do Sul voltado para o termo "globalização", que foi a principal referência dos anos noventa nos mais diversos domínios de atividades e circunstâncias do mundo pós-Guerra Fria, aparentemente como a verdade absoluta para solucionar os problemas do mundo.

Este termo é derivado de políticas neoliberais no início dos anos oitenta, através da difusão da abertura da economia de mercado dos Estados-Nações. Porém, esta proposta obscureceu os direitos dos povos, principalmente nos paises periféricos, onde houve um aumento da "injustiça social" e as "lutas de classes" e de "libertação" demonstram-se como fenômeno terminado, como conceitos obsoletos.

Palavras-Chave: Estado de Bem-Estar Social. Exclusão. Globalização. Direito. Neoliberalismo.

\section{ABSTRACT}

This research analyzes the absence of the State of Law and the consequently fell down of the Welfare State, which directly relates to the social exclusion in South America. The main emphasis is put on the political and economical speech in South America and the context of globalization, which was the principal reference of the 1990s in the most diverse spheres of activities, and specific context of the Post-Cold War.

Globalization has its original meaning in neoliberal policies of the beginning of the 1980s, when the market economies of the Nation-States started. When the process of globalization spread out in the 1980s, it consequently gave origin to the absence of rights of the peoples, specifically in the context of non-developed countries, where the social

\footnotetext{
* Alexandre Reis Nascimento é bacharelando em Relações Internacionais pelo UniCEUB. Trabalho elaborado sob a coordenação da Prof $^{a}$ Dr $^{a}$ Renata de Melo Rosa e do Prof. Marco Antonio de Meneses Silva do UniCEUB. Esta pesquisa recebeu o apoio do Deputado Cleonâncio Fonseca, e foi revisado pelo Prof. José Alfredo Nascimento, Diretor da Universidade Tiradentes, Aracaju/SE.
} 
injustice, as well as the classes struggles and the demand for freedom show themselves as an end phenomenon imbued with old fashioned concepts.

KEY-WORDS: Welfare State. Exclusion. Globalization. Law. Neoliberalism.

\section{Introdução}

As políticas sul-americanas têm, em sua implementação, nos meados da Guerra Fria, características altamente repressivas, que geraram mais problemas que soluções em termos políticos e sociais ${ }^{2}$.

\footnotetext{
“Quando as ditaduras eram responsáveis por torturar presos políticos, pode-se dizer que os governos constitucionais emergentes que adotaram programas rígidos de ajuste econômico estrutural são agora responsáveis por atos de repressão e exclusão, inclusive tortura e condições deploráveis de detenção, afetando de modo particular os não-privilegiados que já existiam e os novos não-privilegiados que foram gerados por esses programas ${ }^{3,}$.
}

O cenário enfocado pela autora $O$. Bolivar, trata de uma realidade eminente na América Latina, na qual um plano de ação institucional diretamente ligado aos países hegemônicos, no período da Guerra Fria, contribuiu para a implantação de um modelo político econômico que era o neoliberalismo. Onde a exclusão social e a manutenção do statos quo da miséria foram utilizados como ferramenta para criação do Estado desenvolvimentista - segundo documentos referentes à $2^{\mathrm{a}}$ sessão da Comissão Econômica para a América Latina (CEPAL), em junho de 1949, os Estados Unidos se mantiveram numa posição política representativa deste modelo de sistema ${ }^{4}$.

Este tipo de ferramenta tinha como princípio a alienação popular através da pobreza, mecanismo utilizado para fazer com que as pessoas não tenham a capacidade interpretativa

\footnotetext{
2 JELSMA, Martin / RONCKEN, Theo. Democracias Bajo Fuego. Drogas y Poder en América Latina. Ed. Brecha. Pág. 7.

${ }^{3}$ O., Ligia Bolivar, Democracia Violência e Injustiça, Ed. Paz e Terra, 2000. Pág. 58.

${ }^{4}$ CERVO, Amado Luiz. Relações Internacionais da América Latina: velhos e novos paradigmas. Brasília: Instituto Brasileiro de Relações Internacionais 2001.
} 
de entender que há algo errado nos investimentos sociais e na maneira de como estão sendo tratadas. Isto é bem notório em meados dos anos 70, no exemplo das ditaduras militares implantadas na América do Sul, mediante uso repressivo da violência, dificultando em muito a relação entre Estado e sociedade civil. Afinal, as classes trabalhadoras e desempregadas sofrem tanto a exclusão econômica, como jurídica e política.

O indivíduo, nesta concepção, não é mais que do que o espelho da sociedade, à qual tem necessariamente que submeter-se. Neste caso, não há outra saída para os que almejam a independência senão marginalizarem-se, recusando o social como totalidade, na ilusão de que, pela transgressão, poderão finalmente expressar sua singularidade e, portanto, sua liberdade. Um mundo ainda convencional, apesar de toda a transgressão ${ }^{5}$.

\footnotetext{
“Os movimentos totalitários tiveram o objetivo de organizar as massas e não as classes, eles foram possíveis onde existiam massas que de uma certa forma se apegaram a organização política, entenda-se por massa as pessoas neutras que são politicamente indiferentes e raramente exercem seu poder de voto, apáticas e incapazes dos processos que as envolvem ${ }^{6}$ ".
}

Desta forma podemos afirmar que o processo de expansão neoliberal adotou princípios totalitários, pois usam e abusam das liberdades democráticas com o objetivo de suprimi-las. Não porque seus líderes sejam diabolicamente espertos ou as massas sejam completamente ignorantes. As liberdades democráticas podem basear-se na igualdade de todos os cidadãos perante a lei; mas só se consolidam e funcionam organicamente quando os cidadãos pertencem a agremiações ou são representados por elas, ou formam uma hierarquia social e política. A indiferença em relação aos negócios públicos e a neutralidade em questões de política não são, por si, causas suficientes para o surgimento de movimentos totalitários. A sociedade competitiva de consumo criada pela burguesia gerou apatia, e até mesmo hostilidade, em relação à vida pública, não apenas entre as camadas sociais exploradas e excluídas da participação ativa no governo do país, mas acima de tudo entre sua própria classe. O longo período em que a burguesia se contentou em ser a classe social dominante sem aspirar ao domínio público, relegado à aristocracia, foi seguido pela

\footnotetext{
${ }^{5}$ HABERMAS, J. El Discurso Filosófico de la Modernidad. Madrid, 1980.

${ }^{6}$ ARENDT, Hannah, As Origens do Totalitarismo. As origens do totalitarismo. SP, Cia. das Letras, 1989.
} 
era imperialista, durante a qual a burguesia tornou-se cada vez mais hostil às instituições nacionais existentes, passando a exigir o poder político e a organizar-se para exercê-lo.

Fazendo uma reavaliação dos custos e benefícios mundiais da Globalização, praticamente um quarto século posterior à aceleração do processo, com o discurso neoliberal dos paises centrais de que os governos não são soluções e sim problemas, a saída se encontrava no setor privado e na abertura das fronteiras ao mercado internacional. Desde então vimos que se privatizou demais, mas com uma ressalva com relação ao cidadão: o "povo" ganhou ou perdeu direitos?

Os paradigmas da política internacional encontram-se em tensão permanente no mundo moderno, com uma forte tendência ao enfraquecimento das propostas clássicas de "soberania nacional" em favor das propostas da "globalidade", traduzidas quase que de forma literal em meras propostas de abertura de mercados, a qual não tem como prioridade a garantia dos direitos coletivos e individuais. Quando o ser humano acostumado a pensar dogmaticamente se vê sem dogmas, dá-se conta de que está acostumado a não pensar. Na forma dominante de pensar e falar, o dogma triunfante é a globalidade "desideologizada", os direitos individuais sem direitos sociais, o laissez-faire do neoliberalismo conservador.

Segundo Emir Sader, a América Latina contemporânea se converte na terceira grande cena de experimentações neoliberais. Este continente foi testemunha da primeira experiência neoliberal sistemática do mundo. Referência específica à realidade política e econômica do Chile sob a ditadura de Pinochet. Regime que inaugurou, de fato, o ciclo neoliberal da história contemporânea. Naquele cenário, naturalmente, a inspiração teórica da experiência "pinochetista" era mais norte-americana.

\footnotetext{
“O neoliberalismo chileno pressupunha a abolição da democracia e a instalação de uma das mais cruéis ditaduras militares do pós-guerra. Mas a democracia em si mesma - como explicava incansavelmente Hayek - jamais havia sido um valor central do neoliberalismo. A liberdade e a democracia, de acordo com Hayek, podiam facilmente tornar-se incompatíveis, se a maioria democrata decidisse interferir com os direitos incondicionais de cada agente econômico de dispor de sua renda e de sua propriedade como quisesse ${ }^{7}$, .
}

\footnotetext{
${ }^{7}$ SADER, Emir. Pós-neoliberalismo. As políticas sociais e o Estado democrático. São Paulo/Rio de Janeiro: Paz e Terra, 2003, p. 19.
} 
"A economia chilena cresceu a um ritmo bastante rápido, mantido pelos governos pósPinochet. Por outro lado, a Bolívia, em 1985, já havia aperfeiçoado seu tratamento de choque na relação entre Estado e sociedade civil, e a partir das suas relações com os norteamericanos, a obrigou a quebrar, sem necessidade explicar melhor esta expressão, um movimento operário poderoso, que favorecia a hiperinflação ${ }^{8}$.

“Em seguida, em 1989, a Argentina teve em seu comando do Estado o ex-presidente Carlos Menem. No mesmo ano, o $2^{\circ}$ governo de Carlos Andes Perez, na Venezuela; e a eleição de Fujimore no Peru, em 1990. Nenhum desses governantes confessou ao povo, antes de ser eleito, o que efetivamente faria depois de eleito. Eles prometeram exatamente o oposto das políticas radicalmente antipopulistas que implementaram nos anos $90^{9,}$.

\begin{abstract}
"Seria arriscado afirmar que somente regimes autoritários podem impor com êxito políticas neoliberais na América Latina. A Bolívia, onde todos os governos eleitos depois de 1985, tanto de Paz Zamora, quanto de Sanchez Losada, continuaram com a mesma linha, comprovando o oposto. A lição que fica da longa experiência boliviana é esta: há um equivalente funcional ao trauma da ditadura militar como mecanismo para induzir democrática e não coercitivamente um povo a aceitar políticas neoliberais das mais drásticas. Este equivale a hiperinflação ${ }^{10,}$.
\end{abstract}

As ofensivas das burocracias militares obedeciam aos estrategistas da guerra interna e as políticas de ajuste, que desde então o Fundo Monetário Internacional (FMI) e o Banco Mundial (BM) impuseram à América Latina, levaram a um empobrecimento da população e a um enfraquecimento dos trabalhadores e empregados. Daí a necessidade de dominar o antigo movimento operário e eliminar as conquistas sociais e os direitos trabalhistas ou rurais obtidos pelos trabalhadores, ao longo de várias décadas, o que exigiu a aplicação de políticas repressivas para conter as massas, gerando um dos mais importantes fatores para a formação do "status quo" da pobreza na América Latina.

A aplicação destas políticas ocorreu em desacordo com a Organização Mundial da Saúde (OMS), para a qual o mundo tem como seu maior fator de mortalidade e principal fonte de doença e sofrimento, razão listada quase no fim da Classificação Internacional de Doenças sob código Z59.5 traduzido como extrema pobreza. Onde descreve: "saúde é um

\footnotetext{
${ }^{8}$ SADER, Emir. Pós-neoliberalismo. As políticas sociais e o Estado democrático. São Paulo/Rio de Janeiro: Paz e Terra, 2003, p. 20.

${ }^{9}$ Idem, p. 20.

${ }^{10}$ Idem, p. 21
} 
estado de completo bem-estar físico, mental e social, e não apenas a ausência de doenças e enfermidades”. Desta forma, fica fácil observar a ligação entre a pobreza, a privação da ascensão social e do direito à integridade física, ao conceito de saúde pública, mostrando que o desinteresse dos governos latino-americanos com as questões sociais neste período, em decorrência de um maior ênfase para a implantação de um sistema neoliberal, transformou uma grande parte de sua população sadia em potenciais doentes, segundo a OMS.

Segundo Hannah Arendt ${ }^{11}$, Hobbes foi o verdadeiro filósofo da burguesia, porque compreendeu que a aquisição de riqueza, concebida como processo sem fim, só pode ser garantida pela tomada de poder político de forma a assegurar uma contínua geração de poder que seu Leviatã condena como infinita e incontrolável. Desta forma, fica notório que a solução para implantar este poder político-ideológico latino-americano, depois do período do pós-guerra, era manter um Estado forte em sua capacidade de romper o poder das massas populares e controlar as finanças, mas contida em todos os gastos sociais e nas intervenções econômicas.

Como as pessoas excluídas, segregadas dos meios de ascensão social e dos meios de informações, podem ter uma vida digna de um ser humano que não passa fome? Como é possível reverter esta situação? A maior parte dos pesquisadores que estuda a pobreza e a transgressão social diz que é pelos meios ilícitos (mesmo que seja de forma transitória) ou por uma grande sorte na vida.

O discurso sobre a globalidade não só obedece a uma realidade epistêmica legítima, mas está sendo usado também para uma "reconversão de dependência ${ }^{12}$ ". Freqüentemente contribui para ocultar ou ocultar-se dos efeitos da política liberal neoconservadora nos países de Terceiro Mundo, principalmente na América Latina, e os problemas sociais cada vez mais graves da maior parte da humanidade. Nas linhas essenciais do mundo atual tornase indispensável à análise histórica, onde primeiramente encontra-se o colonialismo da

\footnotetext{
${ }^{11}$ ARENDT, Hannah, As Origens do Totalitarismo.

${ }^{12}$ CASANOVA, Pablo G. Globalização Excludente. Brasil, Ed. Vozes, 47-50.
} 
idade moderna, um colonialismo global ${ }^{13}$, que hoje é também adicionado ao ideário neoliberal e pós-moderno. A reconversão é em grande parte uma recolonização ${ }^{14}$.

Com a liberalização da economia, desregulamentação do setor financeiro, privatização e desnacionalização de riquezas naturais, de empresas bancárias, industriais, agropecuárias e de antigos serviços públicos como estrada de ferro, eletricidade, telefonia, correios, água potável, escolas, hospitais, fizeram com que essa radical tendência de concentração das corporações na economia global, adicionada aos intensos processos que transferiram o imenso patrimônio dos Estados Nacionais para o controle das grandes corporações, provocasse desta forma uma rápida mudança dos atores do cenário econômico em inúmeros países, com importantes decorrências sociais, políticas e culturais.

\footnotetext{
"No momento em que a dinâmica da globalização passa a mostrar com nitidez sua face socialmente perversa e uma crise de legitimidade das representações políticas atinge até os países capitalistas de maior tradição de estabilidade democrática, surgem graves tensões entre os problemas de identidade, autoridade e igualdade. Torna-se uma questão obrigatória que as estratégias de crescimento, especialmente dos grandes países da periferia, contenham necessariamente políticas redistributivas que enfrentem a questão crônica da concentração de renda e da pobreza. Nessas circunstâncias, do ponto de vista da democracia, o desafio de reconstruir a governabilidade - o que equivale a construir o próprio Estado - passa a ser crítico em razão da deterioração difusa do tecido social, com conseqüência surgimento de espaços onde a autoridade estatal não tem tido condições de fazer valer de modo efetivo ${ }^{15}$ ".
}

Com uma política de dessindicalização dos trabalhadores, houve uma redução de salários, na descentralização dos grandes sindicatos e na eliminação de jure ou de facto dos direitos que a classe trabalhadora havia conquistado em lutas centenárias; a política de contenção salarial foi combinada com a da inflação e hiperinflação incontíveis, que se acentuaram com as desvalorizações e com um crescente desemprego devido à falência e suspensões em massa.

\footnotetext{
${ }^{13}$ Sobre este problema, v. Casanova, Pablo G. (1994). Colonialisme global et démocratie. in: État et politique dans le tiers-monde. Paris, L'Harmattan, p. 11-73.

${ }^{14}$ CASANOVA, Pablo G. (1999) Globalidade, Neoliberalismo e democracia. in: Globalização Excludente. Brasil, Ed. Vozes, 47-50.

${ }^{15}$ DUPAS, Gilberto. Hegemonia, Estado e Governabilidade: Perplexidades e alternativas no centro e na periferia. São Paulo, Ed. SENAC São Paulo, p. 16.
} 
Habermas, em artigo intitulado "Tirar lições das catástrofes? Retrospectivas e diagnóstico de um século abreviado", propunha que ao fim do Estado de Compromisso corresponde o ressurgimento das crises, como o aumento da pobreza e diversos tipos de exclusões do sistema de emprego, do acesso à educação, à moradia, ao direito a uma renda familiar mínima, resultando na incapacidade, por parte dos indivíduos atingidos, de mudar tal situação a partir de seus próprios meios. E que a ausência de solidariedade "destruirá, inevitavelmente, a cultura política liberal sem a qual as sociedades democráticas não podem desenvolver o universalismo que as caracterizava ${ }^{16,}$.

Hobsbawm vai mais além: "sugere o colapso do poder do Estado. Isso porque, no mundo globalizado, enquanto as leis de mercado determinam o jogo econômico, são os estados territoriais que se constituem em autoridades para com seus cidadãos". E isso, comenta o historiador, "prosseguirá desta maneira, pois os valores de cada ser humano são distintos, não havendo hegemonia que viabilize um estado único, um pensamento único, um controle duradouro sobre os meios da violência. Entretanto, países que convivem com uma distribuição desigual da renda estão à mercê de protestos sociais, cujas respostas dependeriam de políticas públicas ora restringidas pela pressão dos organismos internacionais em favor da redução do poder Estado, enfraquecendo-o tanto como instrumento de controle social como em sua capacidade de exercício de autoridade ${ }^{17,}$. Como sub-produto desse processo, vemos desenvolverem-se poderes paralelos como a máfia, o crime organizado, o tráfico de drogas e mesmo o terrorismo".

É a partir desse quadro que, segundo Milton Santos, "se pode interpretar a serialização de que fala J. P. Sartre em Questions de méthode, Critique de la Rasion dialectique, 1960. Em tais condições, instalam-se as competitividades, o salve-se-quempuder, à volta ao canibalismo, a supressão da solidariedade, acumulando dificuldades para o convívio social saudável e para o exercício da democracia ${ }^{18,}$.

\footnotetext{
${ }^{16}$ HABERMAS, Jurgen. Aprés l'État Nation. Paris: Fayard, 1998, p.9.

${ }^{17}$ HOBSBAWM, Eric. Folha de São Paulo, 14/04/2002.

${ }^{18}$ SANTOS, Milton. Por uma outra globalização: Do pensamento único a consciência universal. $5^{\mathrm{a}}$ Ed. Rio de Janeiro: Record, 2001, p. 54.
} 
"Nos momentos de crescente miséria e desamparo individual, é tão difícil resistir à piedade, quando ela se transforma em paixão, como deixa de condenar a sua própria universalidade, que parece matar a dignidade mais definitivamente do que a própria miséria ${ }^{19}$

\section{Conclusão}

Nossa grande tarefa, hoje, é analisar os fatores que levaram a sociedade à transgressão e a formação de "estados paralelos", por via de resultados das condições formadas para a difusão de um pensamento neoliberal com práticas totalitárias na América Latina. Esse totalitarismo se dá em todas as esferas da sociedade, assim, cabe-nos, indagar diante dessas novas realidades sobre a pertinência da presente utilização de concepções já ultrapassadas de democracia, opinião pública, cidadania, conceitos que necessitam urgentemente de revisão, sobretudo nos lugares onde essas categorias nunca foram claramente definidas nem totalmente exercidas.

Assim, especificamente nas sociedades democráticas, a aspiração à igualdade daí decorrente esbarra, todavia, no sentimento de superioridade que alguns grupos nutrem em relação aos outros, quer por tradição, quer pelos diferenciais preexistentes.

Debater práticas sobre temas centrais nas democracias do século $\mathrm{XX}$, como a apatia, colaboracionismo, apoliticismo e predisposição a violência, bem como compaixão e filantropia como atitude moral, que afetam profundamente o exercício da cidadania, faz-se necessária a elaboração de um projeto acadêmico de longo prazo, que, nesse artigo, não deve ser discutido densamente. Porém, percebe-se que os pobres são considerados socialmente inferiores e, assim, discriminados, consequentemente aceitam as relações de poder como elas se apresentam, o que só tem feito aumentá-los em termos numéricos.

Para muitos autores, como por exemplo Freud $^{20}$, a institucionalização do conflito por debate democrático não foi suficiente para aplacar o ódio e ressentimentos, contidos ou

\footnotetext{
${ }^{19}$ ARENDT, Hannah. O Sistema Totalitário. Lisboa: Dom Quixote, 1978, P. 420.

${ }^{20}$ ANSART, Pierre. História e memória dos ressentimentos. In: BRESCIANI, M. Stella e MAXARA, Márcia. Memórias e Ressentimentos; indagações sobre uma questão sensível. Campinas: Editora da UNICAMP, 2001.
} 
manifestos, entre os desiguais. E esta desigualdade soa mais aguda quando os anseios por aquisição de bens materiais, associado a prestígios sociais, torna-se cada vez mais obsessiva em nossas sociedades, principalmente aqueles com alta concentração urbana, em que os meios de comunicação se ampliam tanto quanto se padronizam os hábitos de consumo. Desta maneira, Hannah Harendt introduz um conceito novo e bastante peculiar no século XX para aqueles que almejam a "ascensão social", por via da transgressão e atos ilícitos, cujo termo, denominado "ralé", assume um significado bastante preciso:

\footnotetext{
“A ralé é fundamentalmente um grupo no qual estão representados resíduos de todas as classes. É isto que torna tão fácil confundir ralé com povo, o qual compreende todas camadas sociais. Enquanto o povo (...) luta por um sistema realmente representativo, a ralé brada sempre pelo homem forte, pelo grande chefe. Porque a ralé odeia a sociedade da qual é excluída e odeia o parlamento onde não está representada ${ }^{21}$ ",
}

Com o fenômeno da globalização do mercado de trabalho, os homens tornaram-se, em escala mundial, seres supérfluos e, para muitos deles, a "ralé", a economia informal (ou oculta) e a criminalidade parecem ser os únicos horizontes que se abrem.

Para fundamentar esta afirmação pode-se fazer uma reflexão sobre pesquisas empiricamente relatadas, como por exemplo, no Brasil, através de trabalhos recentes do Instituto de Pesquisa Econômica Aplicada (IPEA), que exploram a relação entre a pobreza, desigualdade e crescimento do Brasil, que concluiu que "a pobreza no Brasil tem mais a ver com a persistência da desigualdade do que a capacidade da economia de gerar renda ${ }^{22, "}$ Assim, o choque do crescimento na redução da pobreza fica substancialmente reduzido, enquanto o choque de melhorias ainda que marginais na distribuição de renda possa resultar na redução da pobreza, mesmo que seja em níveis modestos.

\footnotetext{
"No setor informal, hoje, atividades empresariais organizadas e ilícitas se valem da impunidade, daquilo que um sociólogo chamou de 'áreas de exclusão da lei' (Dahrendorf). Esses novos agentes vivem, pois, na ordem marcada por um controle impiedoso dos que infringem suas normas, mas são profundamente desorganizadores da sociedade e provoca
}

\footnotetext{
${ }^{21}$ HARENDT. Hannah, op. cit. p. 163 e ss. e p. 399 e ss.

${ }^{22}$ HERRÁN, Carlos Alberto. Reduzindo a Pobreza e a Desigualdade no Brasil. Brasil: Banco Interamericano de Desenvolvimento, $1^{\text {a }}$ ed., 2005, p. 21.
} 
um sentimento insuportável de desordem e incerteza na população urbana, principalmente a pobre ${ }^{23}$ ".

Dentro deste problema, que é de caráter institucional dos Estados-Nações nos dias atuais, conclui-se que a sociedade civil, principalmente dos paises periféricos, em uma óptica sul-americana, fica desamparada e o Estado passa a atender cada vez menos às necessidades sociais, fazendo com que as organizações criminosas passem a agir como provedores sociais, ou seja, provedores da comunidade, como ONGs. Criminosos e assassinos passaram a ser atores sociais pró-ativos, como por exemplo, a formação do Comando Vermelho no Rio de Janeiro, um tipo de assistência social.

Neste cenário, nota-se que há uma desintegração dos elementos da nação que eram mantidos juntos, ou seja, a transformação na maneira de conceber a nação - que antes nos era dada pela confusa representação de uma "pessoa coletiva", de um "organismo" vivendo vida própria, diferentemente da vida dos indivíduos que a compõe ${ }^{24}$ (como comunidade politicamente organizada em território, do qual possui soberania e compartilham costumes e língua) por via do surgimento dos "Estados Paralelos", que são caracterizados pelo Estado como Organizações criminosas, que justificam, segundo Norberto Bobbio, em seu livro As Ideologias e o poder em Crise, "a própria violência considerando-a como uma resposta, a única resposta possível à violência do Estado ${ }^{25}$,, que surgiu, como efeito colateral, a exclusão dos meios de ascensão social e manutenção do Satus Quo da miséria dos pobres por via da implementação de um novo sistema político-econômico, chamado neoliberalismo derivado do pós Guerra Fria.

Sendo assim, os impactos da luta contra a exclusão e a pobreza, na complexa dinâmica dos processos sociais e políticos da América do Sul visando à proposição de políticas que possam reverter a atual conjuntura, devem-se a um histórico processo de formação de excluídos como consequiência de uma ampla implementação de políticas neoliberais desde o início da Guerra Fria.

\footnotetext{
${ }^{23}$ ZALUAR, Alba. Integração Perversa: pobreza e tráfico de drogas. Rio de Janeiro: Editora FGV, p. 60. ${ }^{24}$ BOBBIO, Norberto. Dicionário de Política. Brasília: Editora Universidade de Brasília, São Paulo: Imprensa Oficial do Estado, $12^{\text {a }}$ ed., 2002, p. 796.

${ }^{25}$ BOBBIO, Norberto. As Ideologias e o poder em crise. Brasília: Editora Universidade de Brasília, $4^{\mathrm{a}}$ ed., 1999, p. 95.
} 


\section{Bibliografia}

-JELSMA, Martin / RONCKEN, Theo. Democracias Bajo Fuego. Drogas y Poder en América Latina. Ed. Brecha.

-O., Ligia Bolivar, Democracia Violência e Injustiça, Ed. Paz e Terra, 2000.

-CERVO, Amado Luiz. Relações Internacionais da América Latina: velhos e novos paradigmas. Brasília: Instituto Brasileiro de Relações Internacionais 2001.

HABERMAS, J. El Discurso Filosófico de la Modernidad. Madrid, 1980.

-ARENDT, Hannah, As Origens do Totalitarismo. As origens do totalitarismo. SP, Cia. das Letras, 1989.

-SADER, Emir. Pós-neoliberalismo. As políticas sociais e o Estado democrático. São Paulo/Rio de Janeiro: Paz e Terra, 2003.

-CASANOVA, Pablo G. Globalização Excludente. Brasil, Ed. Vozes.

-Sobre este problema, v. Casanova, Pablo G. (1994). Colonialisme global et démocratie. in: État et politique dans le tiers-monde. Paris, L'Harmattan.

-CASANOVA, Pablo G. (1999) Globalidade, Neoliberalismo e democracia. in: Globalização Excludente. Brasil, Ed. Vozes.

-DUPAS, Gilberto. Hegemonia, Estado e Governabilidade: Perplexidades e alternativas no centro e na periferia. São Paulo, Ed. SENAC São Paulo.

-HABERMAS, Jurgen. Aprés l'État Nation. Paris: Fayard, 1998.

HOBSBAWM, Eric. Folha de São Paulo, 14/04/2002.

- SANTOS, Milton. Por uma outra globalização: Do pensamento único a consciência universal. $5^{\text {a }}$ Ed. Rio de Janeiro: Record, 2001.

-ARENDT, Hannah. O Sistema Totalitário. Lisboa: Dom Quixote, 1978.

-ANSART, Pierre. História e memória dos ressentimentos. In: BRESCIANI, M. Stella e MAXARA, Márcia. Memórias e Ressentimentos; indagações sobre uma questão sensível. Campinas: Editora da UNICAMP, 2001.

HERRÁN, Carlos Alberto. Reduzindo a Pobreza e a Desigualdade no Brasil. Brasil: Banco Interamericano de Desenvolvimento, $1^{\mathrm{a}}$ ed., 2005.

-ZALUAR, Alba. Integração Perversa: pobreza e tráfico de drogas. Rio de Janeiro: Editora FGV. 
-BOBBIO, Norberto. Dicionário de Política. Brasília: Editora Universidade de Brasília, São Paulo: Imprensa Oficial do Estado, 12 ed., 2002.

BOBBIO, Norberto. As Ideologias e o poder em crise. Brasília: Editora Universidade de Brasília, $4^{\mathrm{a}}$ ed., 1999. 